wind tunnel can produce valuable information for detailed interpretations of flow physics. It may provide a thorough understanding of flow interaction between the individual components and its effect on the flow condition at the test section. The CFD simulation could be used to assess the spatial variations that can often be insufficiently covered by experiments. Thus, the derived variables such as shear stress and turbulent kinetic energy (that are difficult to determine experimentally) can be evaluated by numerical simulation [14]. One can integrate experimental measurements with a wind tunnel to corresponding numerical simulations and thus substantially improving the accuracy and efficiency of the flow analysis as compared to ordinary simulation [15].

The present paper incorporates a survey of wind velocity variations inside the test section of a renovated open-type subsonic wind tunnel with experimental and numerical analysis. The experimentation is carried out at five different operating fan speeds from 10 to $30 \mathrm{~Hz}$ in the interval of $5 \mathrm{~Hz}$. The numerical methodology includes the entire configuration of the wind tunnel as a CFD model, to account the impact of various design features on the flow in the test section. The precise correspondence of the numerical simulation with the experiment requires calibration and validation of the numerical results, and this can be achieved by providing stable boundary conditions. A novel approach of system curve generation is utilized to overcome the problem associated with the use of the fantype boundary condition for numerical simulation. In this approach, the system curve based on measured velocity inside the test section and wall static pressure at the downstream end of divergent section, at different fan speeds, is determined. This will take care of resistance throughout the tunnel length and its effect on flow parameters at the test section and correlate the numerical simulation with the experiment to a reasonable accuracy.

\section{Experimental analysis}

The experimental facility comprises of a renovated opentype subsonic wind tunnel with adequate instrumentations to measure the necessary flow parameters. The wind tunnel has a bell mouth at the entrance, which is followed by a settling chamber, convergent section, test section, and divergent section, respectively, as shown in Fig. 1. The bellmouth has a radius of $28 \mathrm{~cm}$. The settling chamber comprises honeycomb and screens. The honeycomb has square cells of $5 \times 5 \mathrm{~cm}^{2}$ and a depth of $20 \mathrm{~cm}$. At a distance of $20 \mathrm{~cm}$ from the honeycomb, there is the first screen of the two screens, which are $30 \mathrm{~cm}$ apart from each other. The convergent section has a contraction ratio of 9 , and the test section is of $60 \times 60 \times 120 \mathrm{~cm}^{3}$. The contraction in use has a third-degree polynomial profile, as shown in Fig. 2. The divergent section has an area ratio of 3.84 and an equivalent cone angle of $12.34^{\circ}$, with square cross section at the upstream end and a circular cross section at the downstream end. At the exit of the wind tunnel, there is an

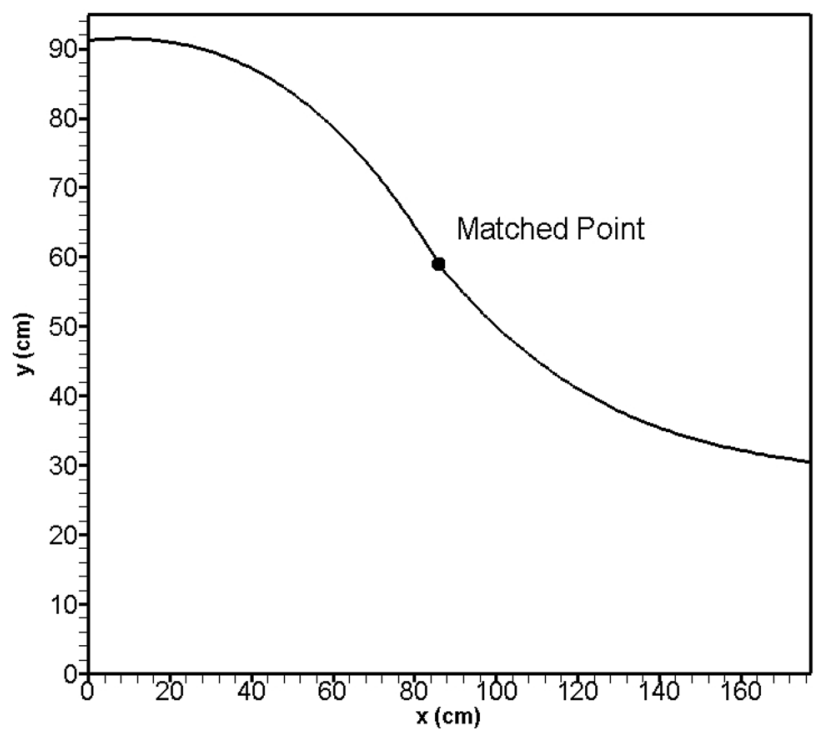

Fig. 2 Schematic of the contraction section (upper half)
Fig. 1 Schematic view of a 2-D wind tunnel; the different components are as follows: (1) settling chamber, (2) contraction section, (3) test section, (4) divergent section, (5) bellmouth, (6) honeycomb, (7) and (8) screens. Sections $a-a, b-b$, and $c-c$ represents the planes about which average static wall pressure is measured

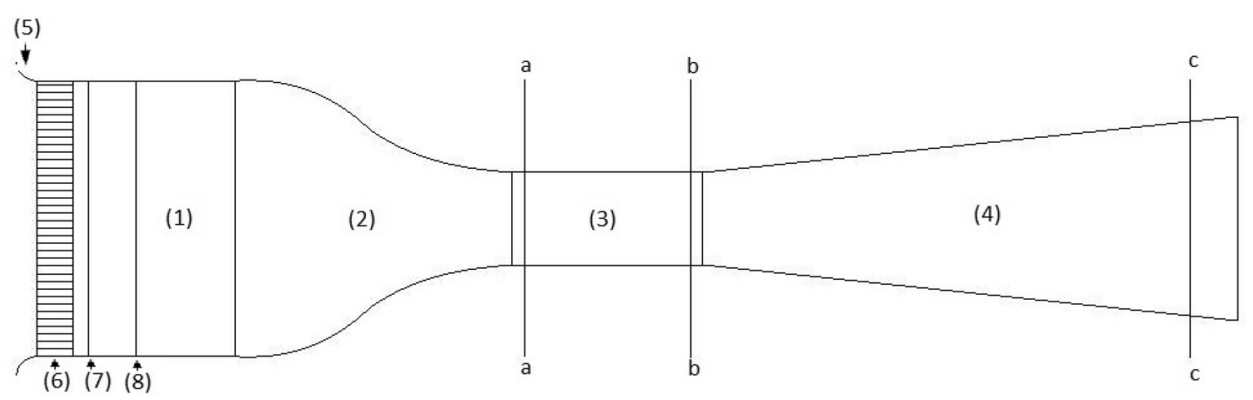


Fig. 3 Open-type subsonic wind tunnel

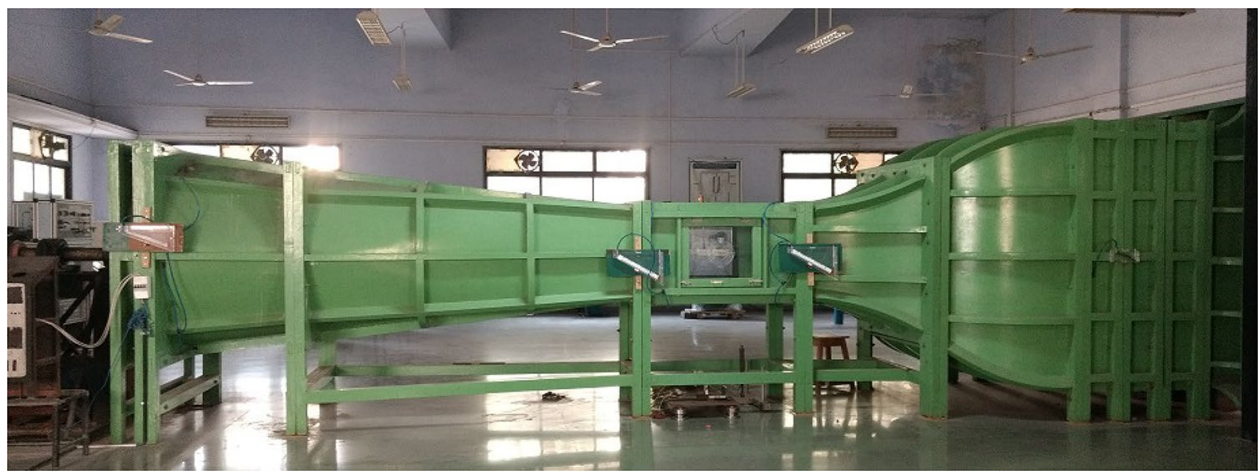

axial flow fan of a $135 \mathrm{~cm}$ diameter which is powered by a $15 \mathrm{hp}$ ac motor. At the specific location along the length of the wind tunnel, as shown by section $a-a, b-b$, and $c-c$, (refer Fig. 1) average wall static pressure is measured. The average static wall pressure is measured by four pressure tapings provided along the periphery of the wind tunnel body at the specified plane locations. These four pressure tapings are connected, which in turn are connected to a $30^{\circ}$ inclined manometers, mounted at the walls of the wind tunnel. Figure 3 shows the general view of the wind tunnel test setup. To measure the wind velocity, a calibrated, Testo made Testo-405i thermal anemometer, which yields mean speed at every second, is used. The precision of the measurement is related to the temperature stability inside of the test section during measurement. It is crucial to perform any measurement in the wind tunnel as stable ambient conditions as possible [16]. Thus, to measure the temperature inside the test section, the same thermal anemometer is used.

Experiments are conducted for five different fan speeds, which are regulated by VFD with the corresponding setting as $10 \mathrm{~Hz}, 15 \mathrm{~Hz}, 20 \mathrm{~Hz}, 25 \mathrm{~Hz}$, and $30 \mathrm{~Hz}$. The wind velocity inside the test section is surveyed by a total of 72 uniformly distributed probe locations. These 72 probe locations were grouped into three horizontal planes, namely upper plane $z u$, middle plane $z m$, and lower plane $z l$, as shown in Fig. 4. Each plane is $10 \mathrm{~cm}$ apart from each other, and the middle plane coincides with the centreline of the wind tunnel. All planes contain six rows of probe locations which are $9 \mathrm{~cm}$ apart and four columns of probe locations which are $12 \mathrm{~cm}$ apart. Thus, the author tries to cover the maximum range of the test section to get a better idea about velocity variations within the test section. To ensure repeatability and hysteresis, measurements at each probe location are repeated twice, i.e., one from maximum to minimum fan speed and other from minimum to maximum fan speed. The average of two data sets is used to designate properties at each probe location. Average static wall pressures are also recorded for all speed range by the inclined manometers.

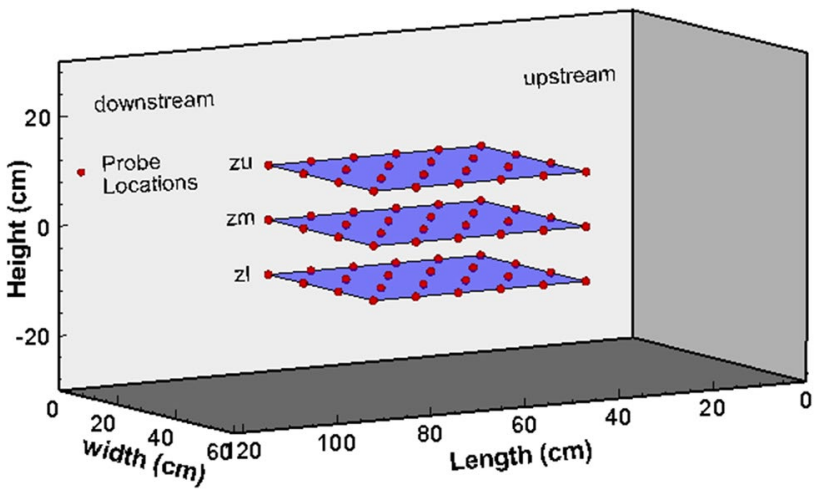

Fig. 4 Graphical representation of probe locations for wind velocity survey inside the test section

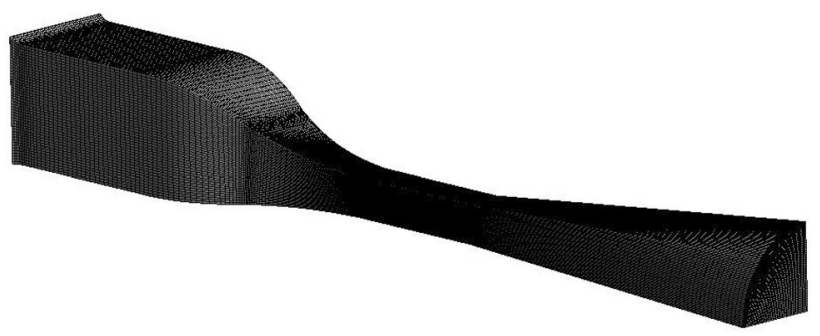

Fig. 5 The meshing of the computational domain

\section{Numerical analysis}

To analyze the detailed flow physics at various locations inside the tunnel, numerical analysis is carried out in a commercially available CFD code ANSYS CFX. Due to the symmetry about the centerline of the wind tunnel, only a quadrant of the wind tunnel is considered as the computational domain. Structured hexahedral elements are used for meshing, as shown in Fig. 5. For the present numerical analysis, certain simplification is made while adopting the boundary conditions. Honeycomb and screens are not individually modeled, but instead, they 
are combined and replaced by choosing proper turbulence intensity at the inlet.

A number of studies on free stream turbulence control using honeycomb and screens of various configurations, individually and also their combinations had been carried out [17-24]. A honeycomb with square cells of $L / d_{\mathrm{h}}$ of $4-12$ and at a downstream of $4 d_{\mathrm{h}}$ has turbulence intensity in between 0.15 and 0.2 [19]. The present wind tunnel has a square cell of $L / d_{\mathrm{h}}$ of 4 , and the first screen is placed at a distance of $4 d_{\mathrm{h}}$ from the downstream end of the honeycomb. So it can safely be assumed that at the entrance of the first screen, the turbulence intensity will be in between 0.15 and 0.2 . The axial turbulence reduction factor for a single screen of different sizes, when experimentally determined, was found to be in between 0.5 and 0.7 ; however, for a series of screens, the total turbulence reduction would be equal to the product of the individual reduction factor [25]. Thus the total reduction factor for a series of two screens is in between 0.25 and 0.49 . So a typical combination of the honeycomb and two screens will bring the turbulence intensity in between 0.0375 and 0.098 , even at worst inlet condition to the settling chamber. Thus for the numerical simulation, the turbulence intensity at the inlet is kept at $10 \%$, considering all possible scenario.

The fan-type boundary condition is a lumped parameter model that allows to input an empirical fan curve that governs the relationship between pressure rise and flow rate. In the present numerical analysis, the fan-type boundary condition is replaced by flow rate (mass flow rate) and a constant pressure jump as boundary conditions for inlet and outlet, respectively. The required mass flow rate and pressure jump for the analysis are obtained from the system curve generated by experimental analysis.

The system curve is an empirical curve that governs the relationship between the total pressure loss and flow rate. The total pressure loss is obtained by measuring the average static wall pressure just at the downstream end of the divergent section. The flow rate is the function of flow velocity and cross-sectional area. Since the numerical simulation is carried out for a quadrant of the wind tunnel, the flow rate will be calculated based on the quadrant cross section of the test section. However, to make the system curve independent of the cross-sectional area, it is obtained against average wind velocity measured at the center of the test section. Figure 6 shows the system curve and operating points of the wind tunnel. Table 1 shows details of the mass flow rate based on average velocity and average static pressure of wall at diffuser end. These mass flow rate and static pressure are given as inlet and outlet boundary conditions, respectively, for numerical analysis.

The outer walls of the wind tunnel have wall-type boundary condition. At the planes of partition, symmetry type of boundary condition is provided. Figure 7 shows the

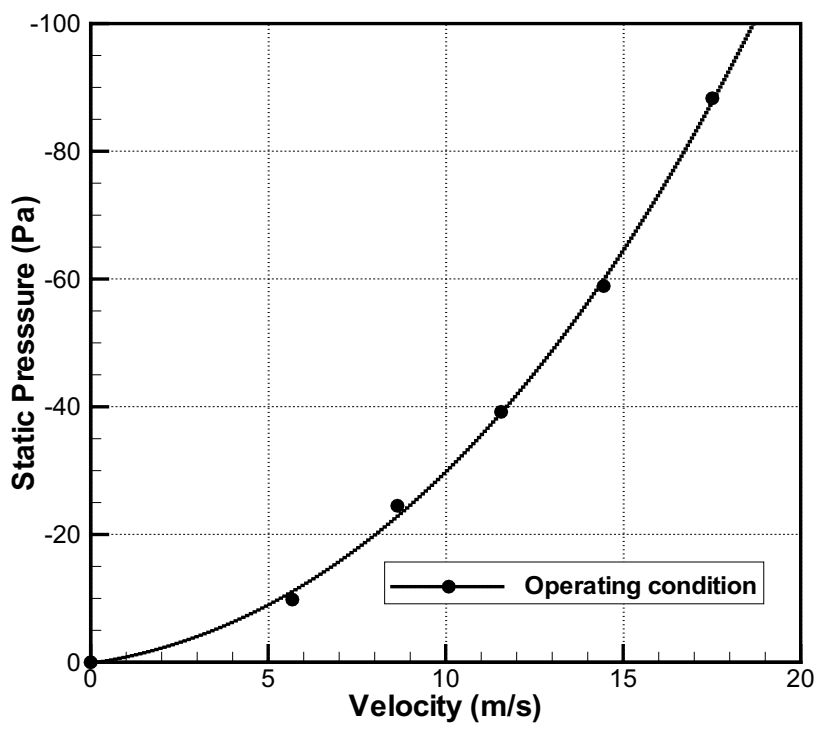

Fig. 6 Graphical representation of system curve

boundary types at all the boundary interfaces. The threedimensional Reynolds-averaged Navier-Stokes (RANS) equations and continuity equation were solved using commercial CFD code Ansys CFX [26]. The turbulence is taken care by standard $k-\varepsilon$ turbulent model $[6,13,14,19,27-29]$.

For grid-independence test, hexahedral elements in the range of $82,834-1,157,464$ are adopted. The variation of static pressure and velocity along the centerline of the test section is observed and represented in Fig. 8. Figure 8 reveals that the variation of pressure and velocity is independent of grid elements beyond 519,108 elements. Hence for further analysis, 519,108 elements are adopted.

\section{Results and discussion}

The wind tunnel is operated at five different speed ranges. At each speed, the survey for the wind velocity, inside the test section, was carried out by measuring the wind velocity and temperature at designated probe locations. The average wall static pressure is also recorded at the designated locations $a-a, b-b$, and c-c, (refer Fig. 1). Numerical simulations, with boundary conditions obtained by utilizing system curve, are carried out and compared with the experimental results. The variation of static pressure along the centerline of the wind tunnel obtained by numerical simulation and the experimentally measured average static wall pressure is shown in Fig. 9. The results show a good qualitative agreement between the experimental and simulation results. However, results suggest overprediction of pressure values in simulation compared to experimental one at the test 
Table 1 The mass flow rate and static pressure for inlet and outlet boundary conditions

\begin{tabular}{llllll}
\hline $\begin{array}{l}\text { VFD } \\
\text { frequency } \\
(\mathrm{Hz})\end{array}$ & $\begin{array}{l}\text { Average } \\
\text { velocity } \\
(\mathrm{m} / \mathrm{s})\end{array}$ & Temperature $(\mathrm{K})$ & Density $\left(\mathrm{kg} / \mathrm{m}^{3}\right)$ & $\begin{array}{l}\text { Mass flow } \\
\text { rate }(\mathrm{kg} / \mathrm{s})\end{array}$ & $\begin{array}{l}\text { Average static wall pres- } \\
\text { sure at diffuser end }(\mathrm{Pa})\end{array}$ \\
\hline 10 & 5.68 & 303.9 & 1.1615 & 0.614 & -9.81 \\
15 & 8.64 & 303.96 & 1.1613 & 0.933 & -24.5 \\
20 & 11.56 & 303.98 & 1.1612 & 1.249 & -39.2 \\
25 & 14.45 & 303.95 & 1.1613 & 1.561 & -58.9 \\
30 & 17.51 & 304 & 1.1611 & 1.891 & -88.3 \\
\hline
\end{tabular}

Fig. 7 Boundary types at the different interfaces

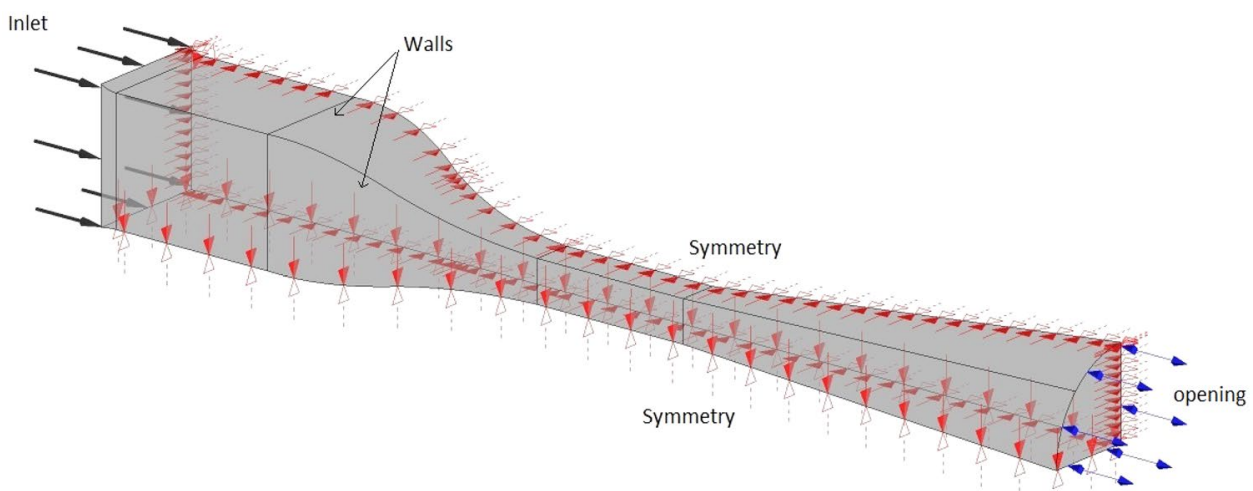

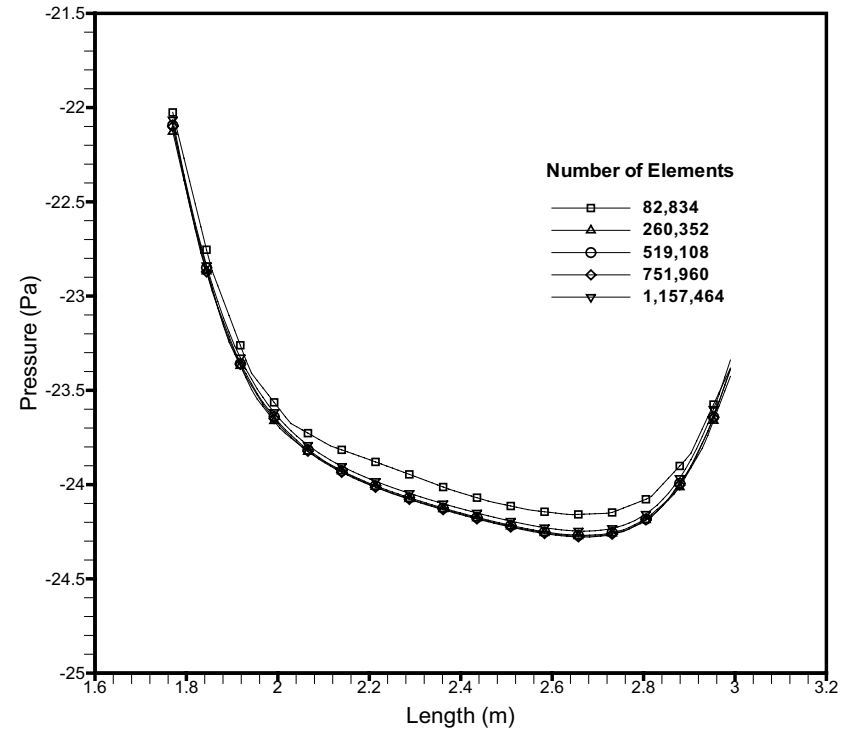

(a) Pressure variation

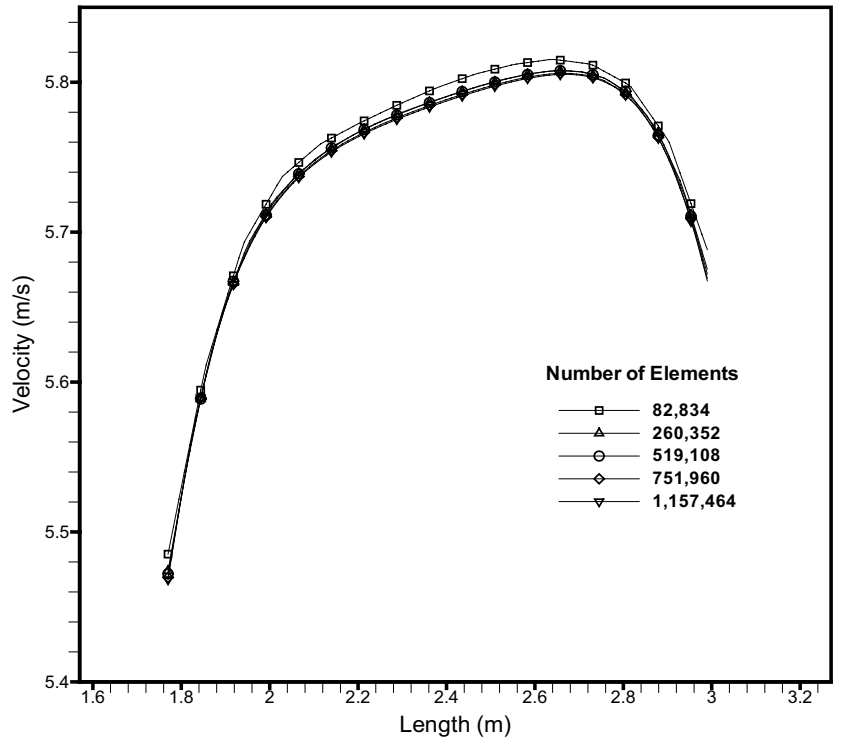

(b) Velocity variation

Fig. 8 Grid independence test

section of the wind tunnel. The major cause of deviation is ideal behavior of flow and its conditions inside the tunnel in case of numerical analysis. Flow as well as its conditions are varying due to effects of environmental change, variation in initial conditions, and flow uniformity index. The inherent shortcomings of the turbulence model also play a role in this discrepancy [30]. The lack of exact initial conditions or boundary conditions in the numerical analysis of the real flow produces numerical solutions, which do not necessarily represent the exact flow field but the one with identical statistics to the relevant flow $[15,31]$. 


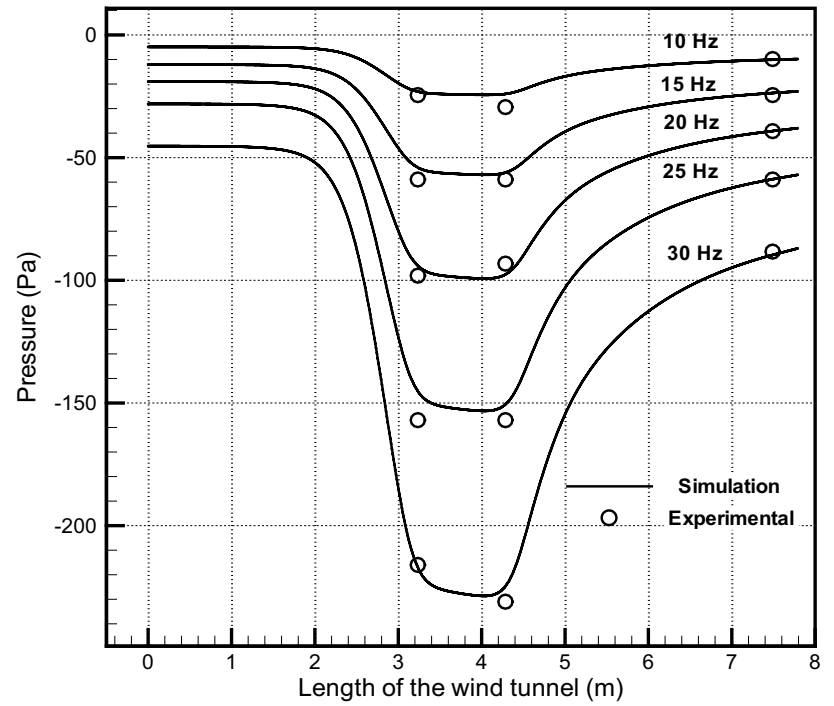

Fig. 9 Variation of static pressure along the centerline of the wind tunnel and experimentally measured average static wall pressure for different fan speeds

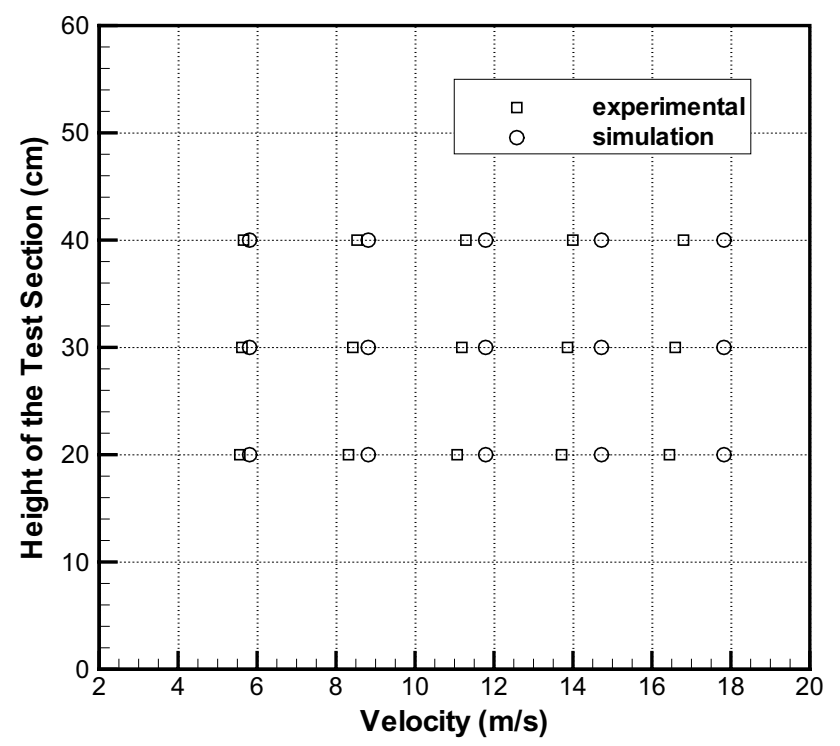

Fig. 10 Variation of average velocities on horizontal planes along the height of the test section, at all speed ranges

A comparison of the velocity variation inside the test section obtained by the numerical simulation and experimental measurement is also made. Figure 10 shows the variation of area-weighted average velocity on horizontal planes $z l, z m$, and $z u$, (refer Fig. 3) for all speed ranges. From Fig. 10, it can be observed that at higher heights (at $z u$ plane), the difference in simulation results and experimental results are relatively small. The maximum difference in the simulation and the experimental results occurs

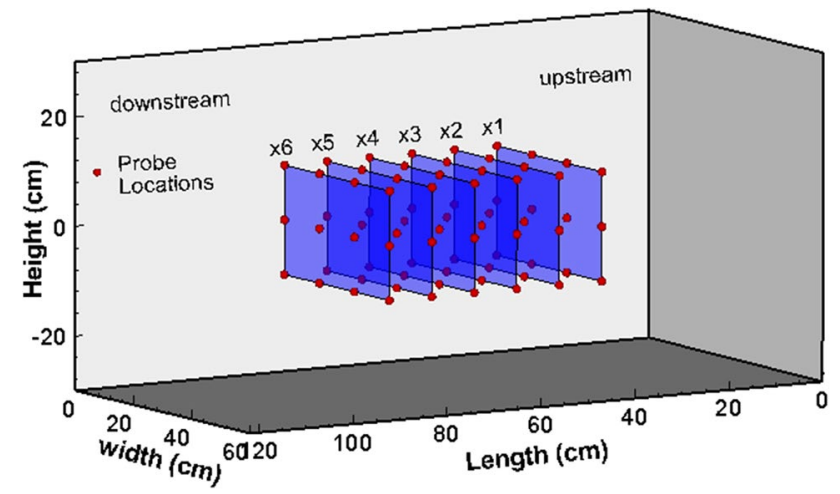

Fig. 11 Probe locations grouped into vertical planes $(x 1, x 2, x 3, x 4$, $x 5$, and $x 6$ )

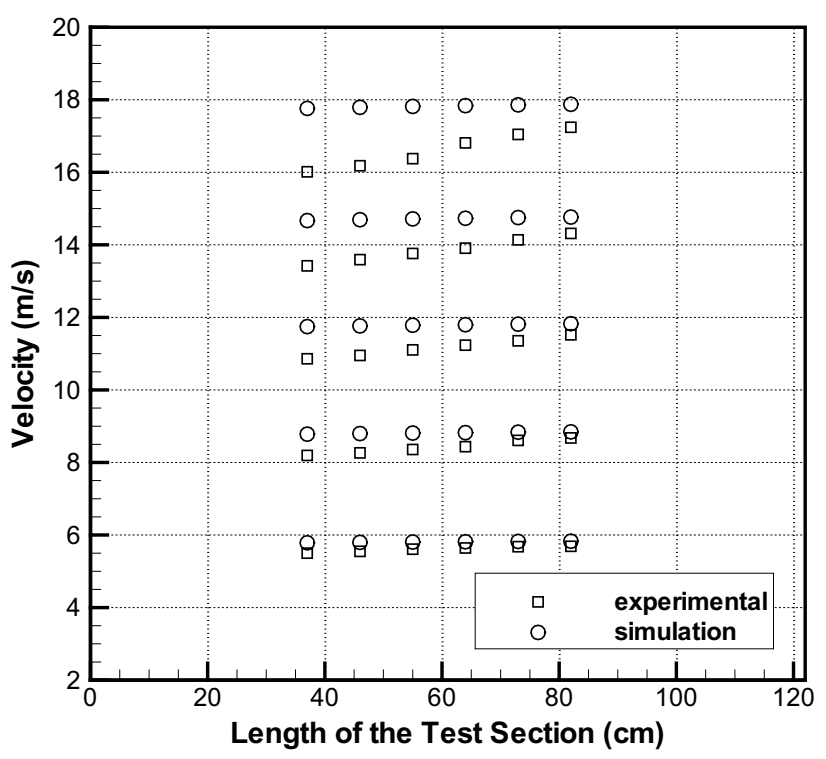

Fig. 12 Variation of average velocities on vertical planes along the length of the test section, at all speed ranges

at the bottom plane ( $z$ l plane), at maximum fan speed, with a magnitude of $1.382 \mathrm{~m} / \mathrm{s}(7.75 \%)$.

For a better idea of the velocity variations within the test section, the same probe locations are grouped into vertical planes $(x 1, x 2, x 3, x 4, x 5$, and $x 6)$, as shown in Fig. 11 , with the $x 1$ plane at the upstream side and $x 6$ plane at the downstream side. Figure 12 shows the variation of area-weighted average velocity on vertical planes $(x 1, x 2$, $x 3, x 4, x 5$, and $x 6$ ), for all speed ranges. From Fig. 12, it can be observed that the velocity variation, as obtained from the experimental measurement, indicates an accelerated flow. In the case of the numerical simulation, the velocity variation remains more or less the same. The maximum difference in the velocity as obtained by the numerical and experimental measurement is found to be $1.749 \mathrm{~m} / \mathrm{s}$ 
(9.84\%) at the upstream end of the test section with a fan speed corresponding to $30 \mathrm{~Hz}$.

Thus the qualitative agreement of the pressure and velocity variation as obtained by the numerical simulation and experimental measurements indicates that the boundary conditions based on the system curve can generate simulation which resembles the actual operating condition with reasonable accuracy. A similar approach of replacing the fan-type boundary condition with other types of boundary condition can also be found in the work of Calautit et al. [13] and suggests that the CFD model can reproduce the wind tunnel measurements with an error of below $10 \%$ for mean velocity, pressure coefficient and turbulent intensity measurement.

For better perception of the numerical and experimental similarity, flow fields are generated for three horizontal planes: $z l, z m$, and $z u$, (refer Fig. 3) covering all the five speed ranges. For generating the flow field, the probe data were interpolated within a confined volume encompassing all the probe locations. The interpolation was performed using a commercially available plotting software-Tecplot. Since the numerical analysis was carried out for just the quadrant of the wind tunnel, to cover the insufficiency of probe data symmetry approach is used, and data were extended for all horizontal planes. Figures 13,14 , and 15 show the comparison of the flow fields as obtained by the numerical and experimental analysis for $z l, z m$, and $z u$ horizontal planes, respectively. The extent of the velocity variation of the above-mentioned numerical and experimental flow fields is obtained with respect to the maximum velocity on the common velocity range scale (contour legend) at any given operating condition.

The velocity contours (refer Figs. 13, 14, and 15) also reveal the acceleration of flow from upstream to downstream in the test section for all three horizontal planes at all speed. On observing the velocity contours of experimental and numerical flow fields at $z /$ plane, at low speed, i.e., at $10 \mathrm{~Hz}$, the extent of the velocity variation for the experimental and numerical flow field is $3.25 \%$ and $0.65 \%$, respectively. As the speed of the fan is increased, the extent of the velocity variation for experimental and numerical flow field increases and reaches a peak of $8.14 \%$ and $1.16 \%$, respectively. Similarly, on observing the velocity contours at the $z m$ plane, the flow field is more or less the same as the flow field on the $z$ l plane at all speed range. The extent of the velocity variation for experimental and numerical flow field, at low speed, is 3.96\% and $0.65 \%$, respectively. As the wind tunnel operates at a higher velocity range, the extent for the experimental and numerical flow field increases and reaches a peak of $8.23 \%$ and $1.16 \%$, respectively. However, on observing the flow field at the zu plane, at a low-speed range, the extent for the experimental and numerical flow field is $1.95 \%$ and
$0.651 \%$, respectively. However, as the higher speed range proceeds, the extent of the velocity variation for experimental and numerical flow field increase and reaches a peak of $5.81 \%$ and $1.16 \%$, respectively.

The extent of the velocity range of the flow fields also depicts the magnitude of non-uniformity in the flow. On observing the extent of the velocity range of the three horizontal planes, the experimental flow field at zu planes appears to be relatively more uniform than the flow field at $z m$ and $z l$ planes. Although the $z u$ and $z l$ planes are symmetric about $z m$ plane, the flow fields on the respective planes are quite different. The flow fields at $z u$ plane appear to be more uniform (maximum extent of velocity variation is $5.81 \%$ ) than the $z /$ plane (maximum extent of velocity variation is $8.14 \%$ ). This is on account of the dynamic oscillations experienced by the sensing probe mounted at the end of the telescopic arm of the measuring instrument. The models supported by a cantilever arm (sting) inside the test section often experiences dynamic oscillations due to unsteady flow and induces an error in the measurements [32].

It is to be noticed that the velocity range of the numerical flow fields mostly covers the peaks of the contour legend. The high gauge pressure, in case of numerical results (refer Fig. 9), is also a reflection of the high-velocity head inside the test section. This implies that numerical flow fields overpredict. This overprediction of the velocity field could also be because of inadequate mass flow rate provided at the inlet boundary conditions besides the inherent shortcoming of the turbulent models and lack of exact boundary or initial conditions. The Log-Tchebycheff method, which accounts for the velocity profile, can provide accurate flow rate [33, 34]. However, due to certain constraints in the accessibility of the test section, the mass flow rates are calculated using average (time-averaged) velocity measured at the centerline of the test section. Generally, the centreline wind velocity in the test section is higher than the average velocity and using the centreline velocity for mass flow rate calculation will produce a higher mass flow rate. For a better prediction from numerical analysis, authors suggest Log-Tchebycheff method for obtaining the flow rates.

\section{Conclusion}

Experimental and numerical analysis of an open-type subsonic wind tunnel is carried out. For accurate correspondence of the numerical results with experimental results, stable boundary conditions are required in the numerical simulation. The boundary conditions based on the experimentally determined system curve are used for accurate correspondence of the numerical simulation with 


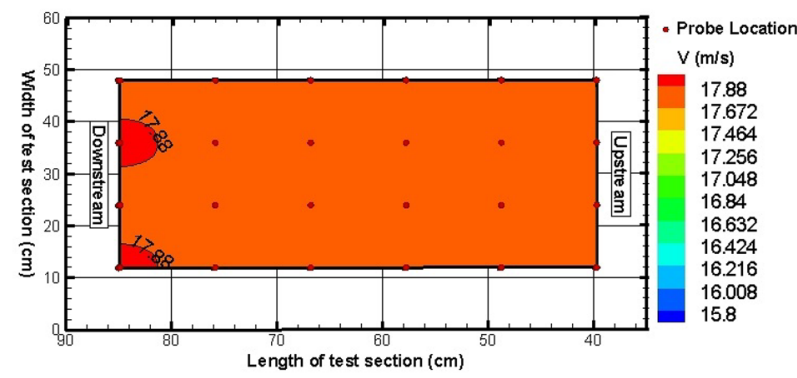

(a) VFD: $10 \mathrm{~Hz}$

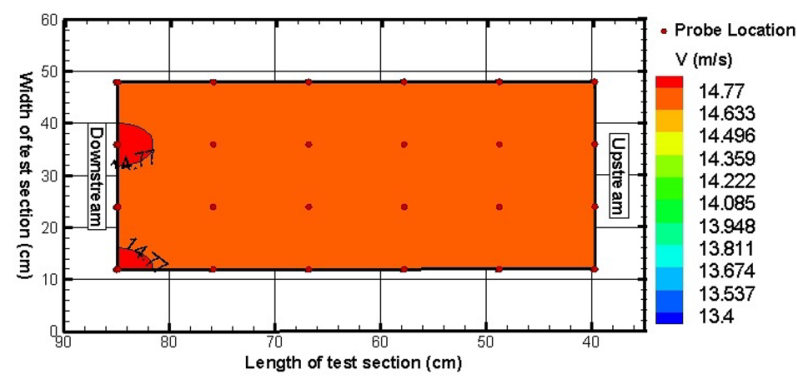

(c) VFD: $15 \mathrm{~Hz}$

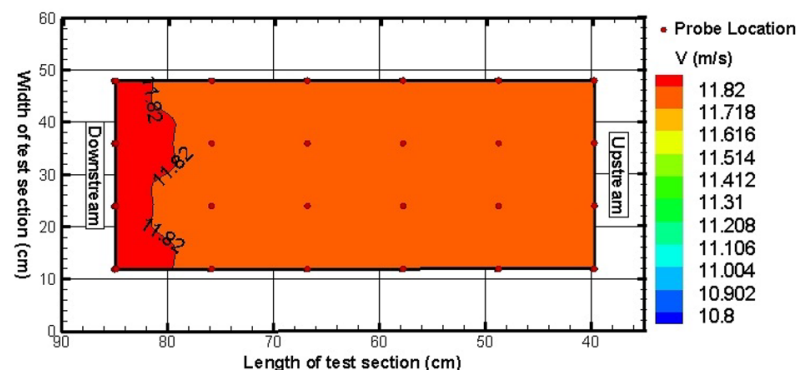

(e) VFD: $20 \mathrm{~Hz}$

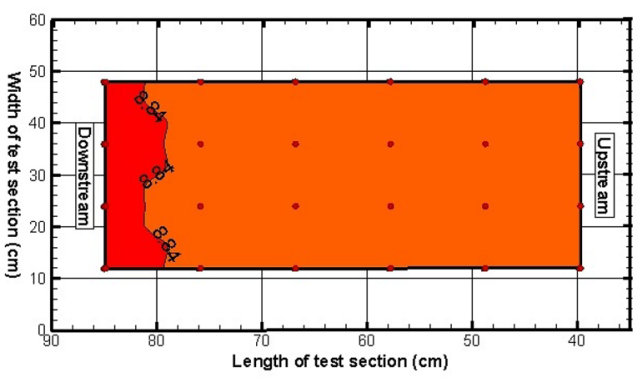

(g) VFD: $25 \mathrm{~Hz}$

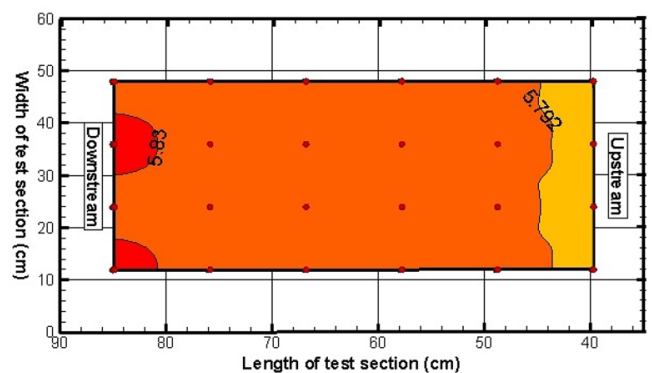

(i) VFD: $30 \mathrm{~Hz}$

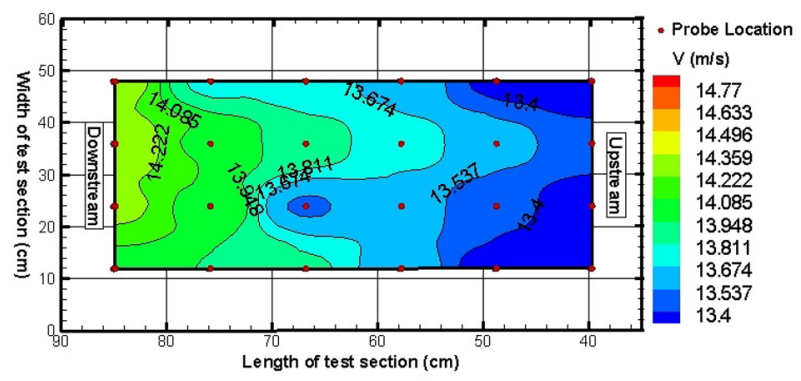

(b)VFD: $10 \mathrm{~Hz}$

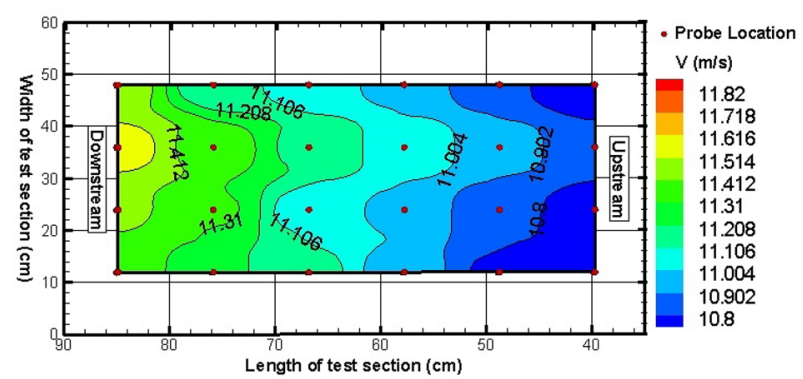

(d)VFD: $15 \mathrm{~Hz}$

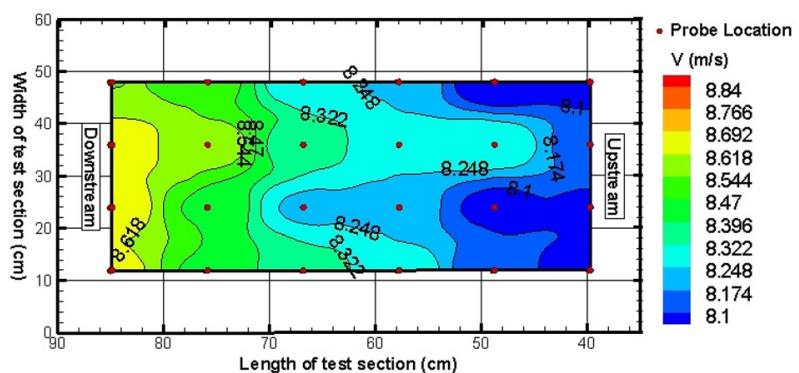

(f) VFD: $20 \mathrm{~Hz}$

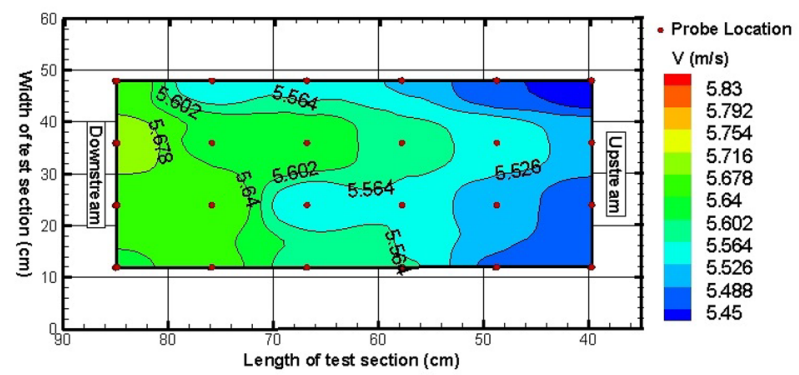

(h) VFD: $25 \mathrm{~Hz}$

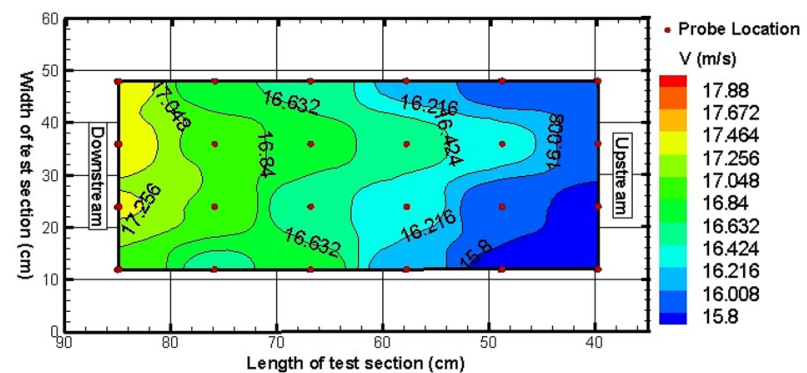

(j) VFD: $30 \mathrm{HZ}$

Fig. 13 Velocity fields on zl plane at a fan speed corresponding to the given VFD setting 


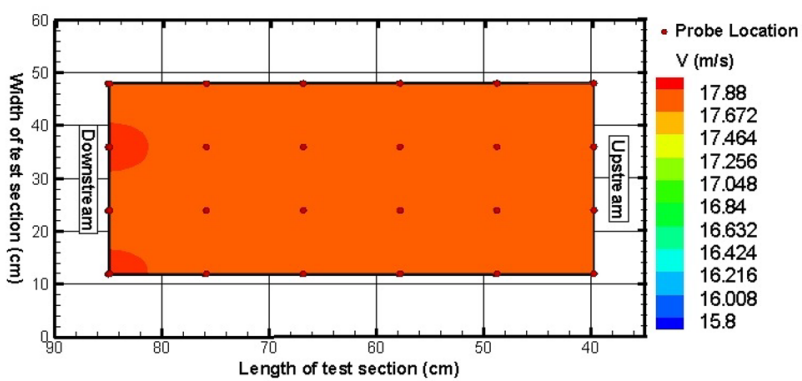

(a) VFD: $10 \mathrm{~Hz}$

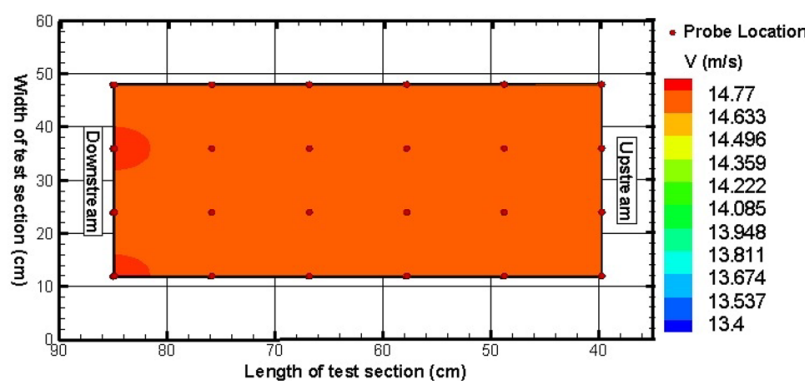

(c) VFD: $15 \mathrm{~Hz}$

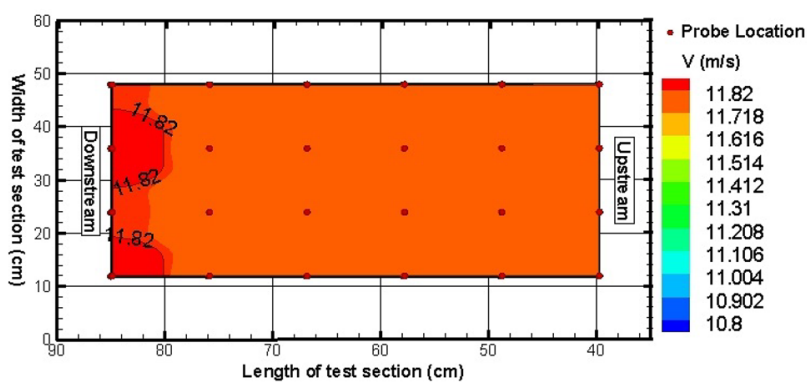

(e) VFD: $20 \mathrm{~Hz}$

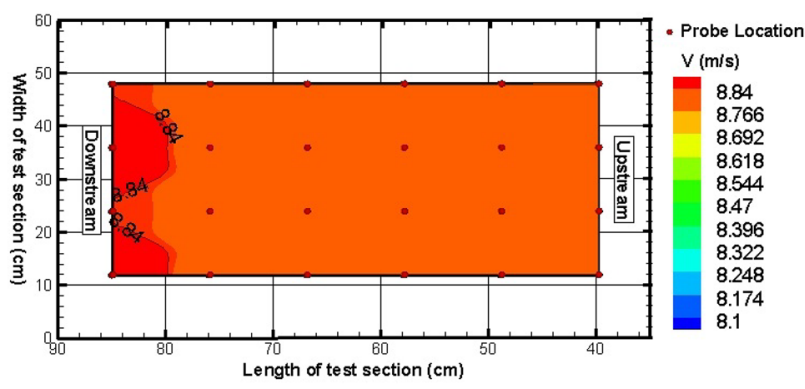

(g) VFD: $25 \mathrm{~Hz}$

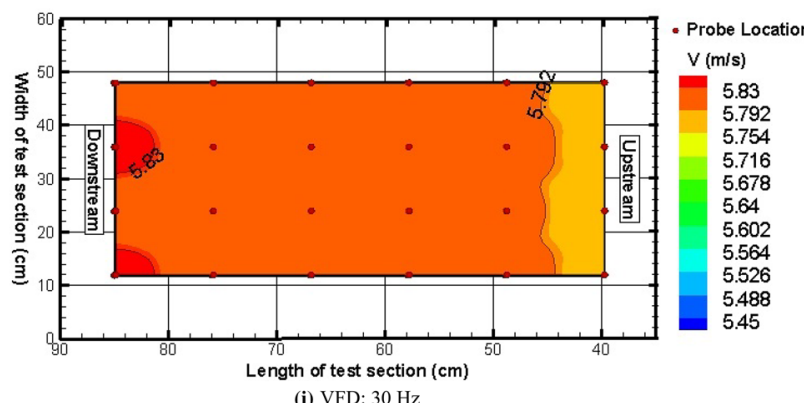

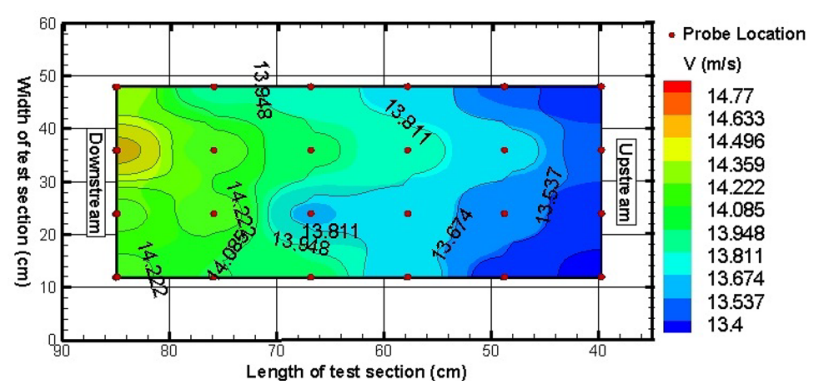

(b) VFD: $10 \mathrm{~Hz}$

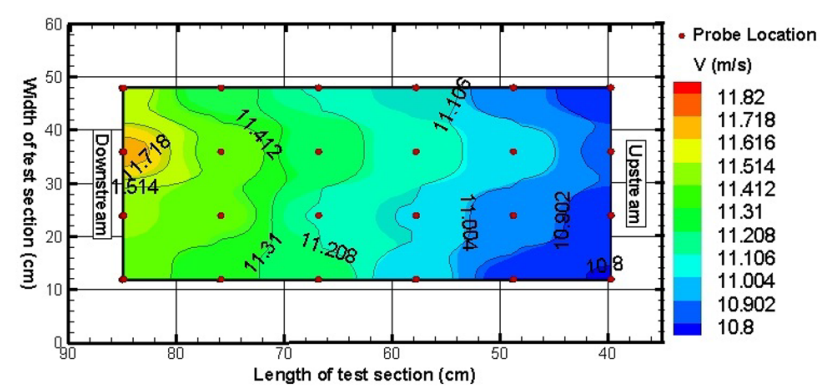

(d) VFD: $15 \mathrm{~Hz}$

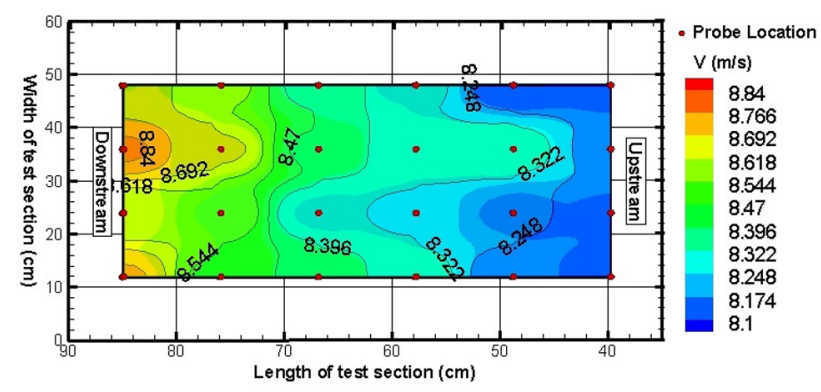

(f) VFD: $20 \mathrm{~Hz}$

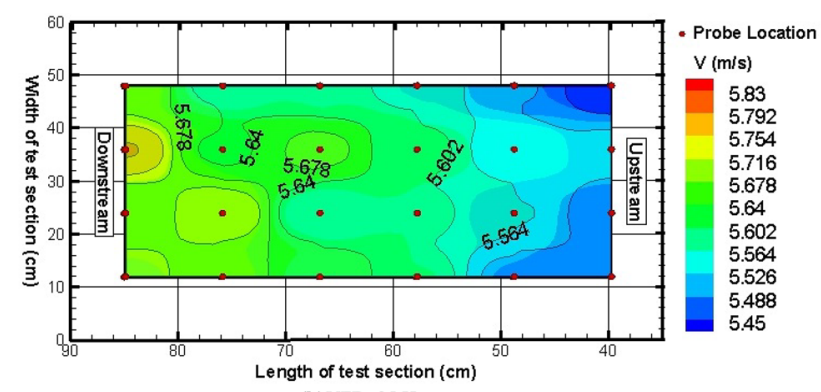

(h) VFD: $25 \mathrm{~Hz}$

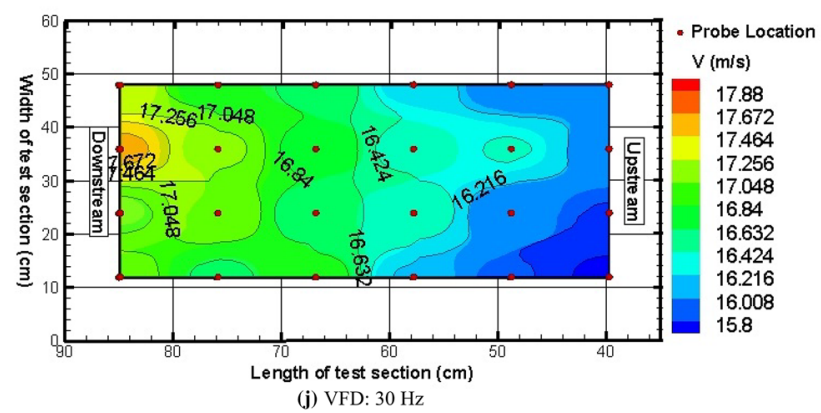

Fig. 14 Velocity fields on zm plane at a fan speed corresponding to the given VFD setting 

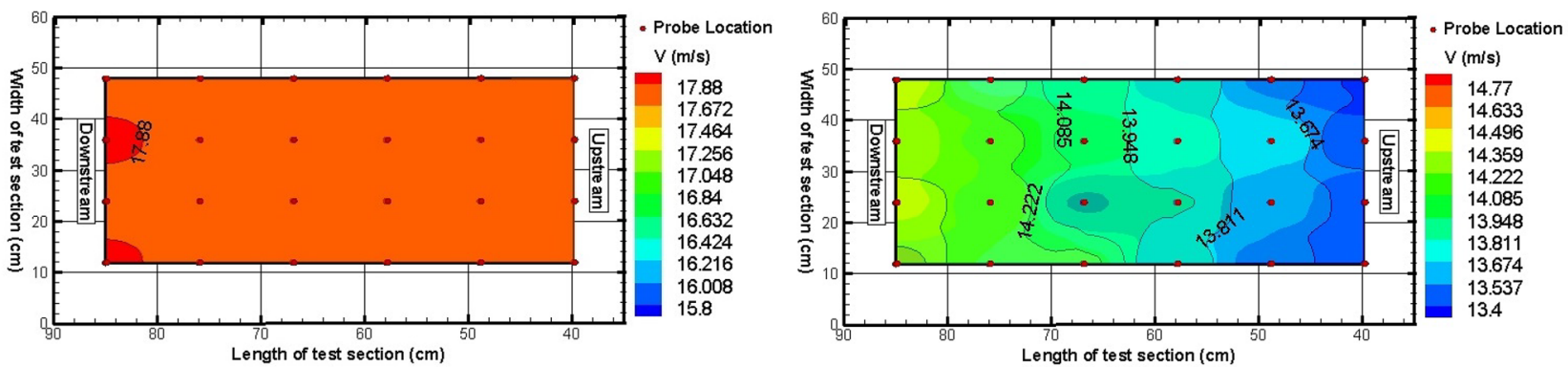

(a) VFD: $10 \mathrm{~Hz}$

(b) VFD: $10 \mathrm{~Hz}$

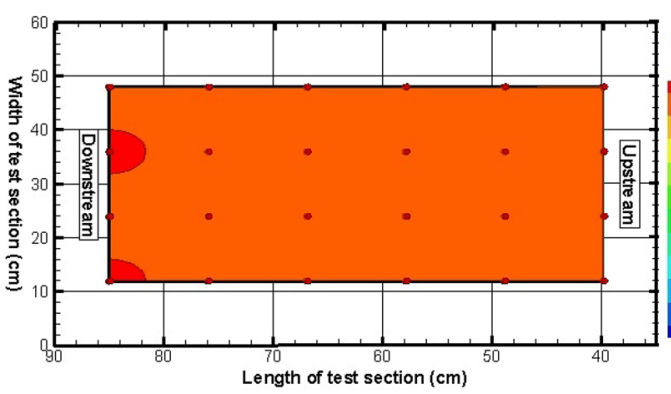

(c) VFD: $15 \mathrm{~Hz}$

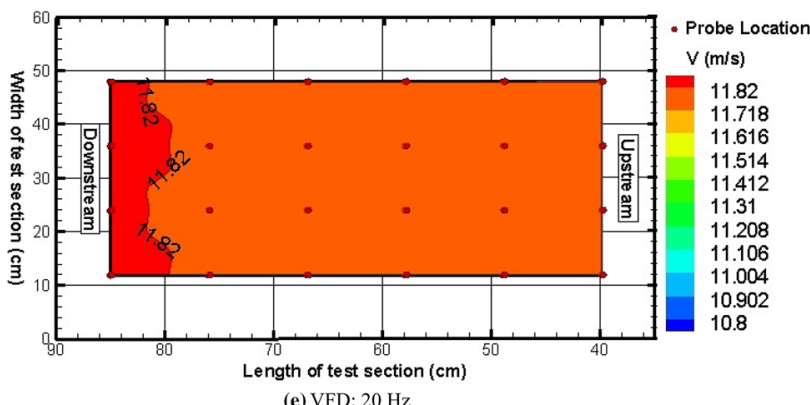

(e) VFD: $20 \mathrm{~Hz}$

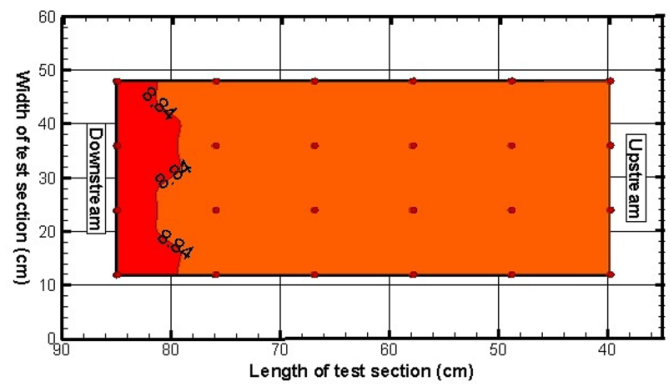

(g) VFD: $25 \mathrm{~Hz}$

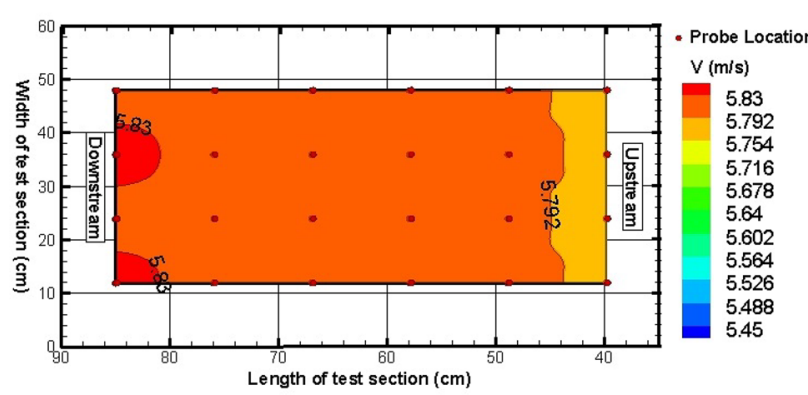

(i) VFD: $30 \mathrm{~Hz}$

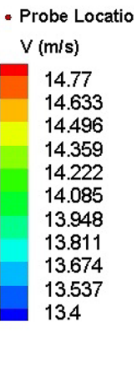

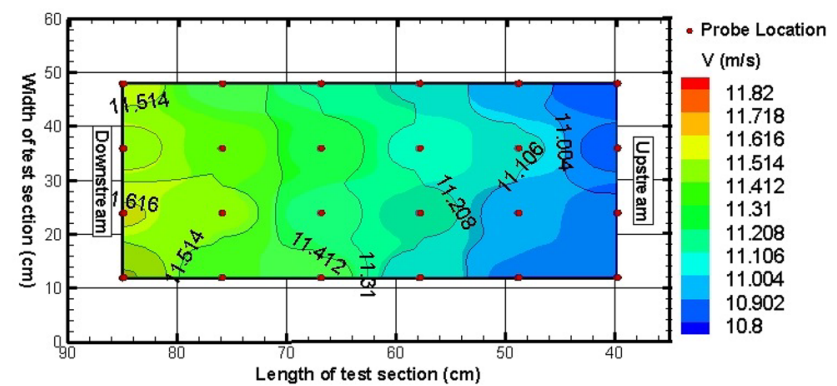

(d) VFD: $15 \mathrm{~Hz}$

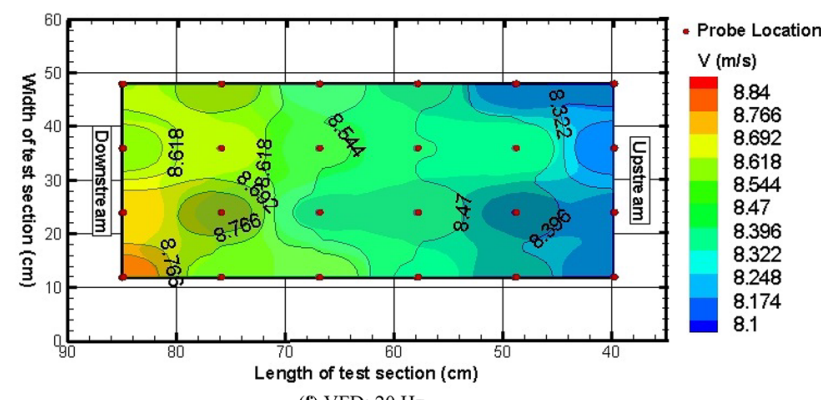

(f) VFD: $20 \mathrm{~Hz}$

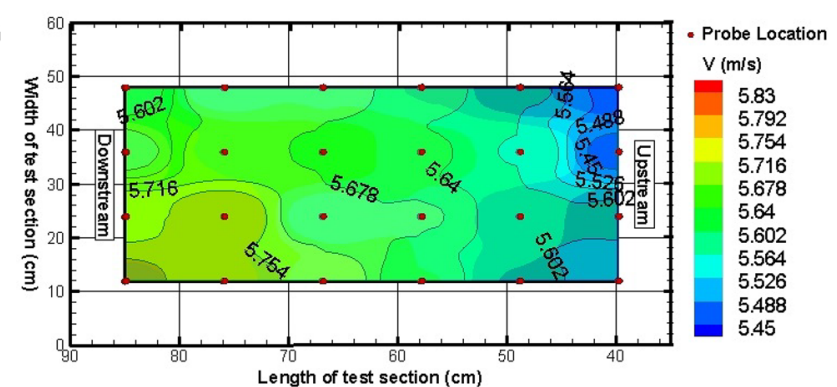

(h)VFD: $25 \mathrm{~Hz}$

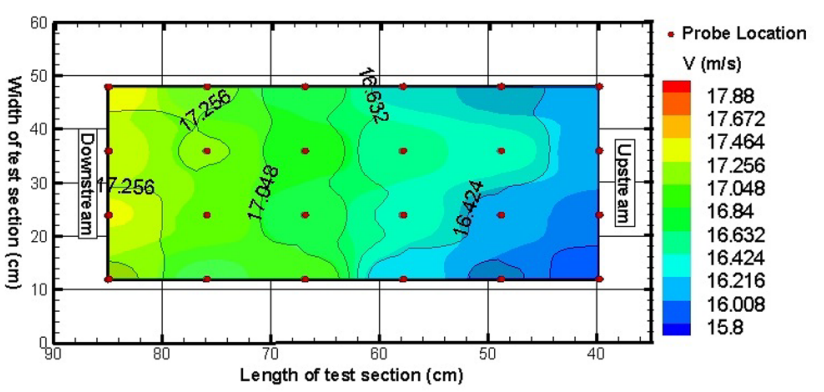

(j) VFD: $30 \mathrm{~Hz}$

Fig. 15 Velocity fields on zu plane at a fan speed corresponding to the given VFD setting 
experiment. A detailed assessment of the numerical and experimental analysis reveals following:

- A comparison of the pressure variations obtained by the numerical simulation and experiment indicates good qualitative agreement. However, small discrepancies in flow properties like static pressure and velocity inside the test section are observed due to ideal and constant initial conditions as well as the inherent shortcoming of the turbulence model. The mass flow rate based on the centreline velocity approach is also a culprit in overprediction of flow properties in numerical simulation.

- A comparison for the similarity of average velocity along the length of the test section shows a maximum error of $9.84 \%$ and along the height of the test section shows a maximum error of $7.75 \%$. Thus, novel approach for boundary conditions is able to produce simulation results with reasonable accuracy.

\section{Compliance with ethical standards}

Conflict of interest On behalf of all authors, the corresponding author states that there is no conflict of interest.

\section{References}

1. Gonzalez Hernandez MA, Moreno Lopez Al, Jarzabek AA et al (2013) Design methodology for a quick and low-cost wind tunnel. Wind Tunn Des Their Divers Eng Appl. https://doi. org/10.5772/54169

2. Bradshaw P, Pankhurst RC (1964) The design of low-speed wind tunnels. Prog Aerosp Sci 5:1-69. https://doi.org/10.1016/03760421(64)90003-X

3. Mehta RD, Bradshaw P (1979) Technical notes design rules for small low speed wind tunnels. Aeronaut J R Aeronaut Soc 83:443-449. https://doi.org/10.1017/S0001924000031985

4. Eckert WT, Mort KW, Jope J (1976) aerodynamic design guidelines and computer program for estimation of subsonic. NASA Tech note 197

5. William H (1999) Low-speed wind tunnel testing. Wiley, New York

6. Gordon R, Imbabi MS (1998) CFD simulation and experimental validation of a new closed circuit wind/water tunnel design. J Fluids Eng 120:311-318

7. Leifsson L, Koziel S (2015) Simulation-driven design of lowspeed wind tunnel contraction. J Comput Sci 7:1-12. https:// doi.org/10.1016/j.jocs.2014.12.004

8. Leifsson L, Koziel S, Andrason F et al (2012) Numerical optimization and experimental validation of a low-speed wind tunnel contraction. Procedia Comput Sci 9:822-831. https://doi. org/10.1016/j.procs.2012.04.088

9. Lummer M (2019) Aircraft noise generation and assessment. CEAS Aeronaut J. https://doi.org/10.1007/s13272-019-00382-5
10. Rodríguez Lastra M, Fernández Oro JM, Galdo Vega $M$ et al (2013) Novel design and experimental validation of a contraction nozzle for aerodynamic measurements in a subsonic wind tunnel. J Wind Eng Ind Aerodyn 118:35-43. https://doi. org/10.1016/j.jweia.2013.04.008

11. Zanoun ES (2017) Flow characteristics in low-speed wind tunnel contractions: simulation and testing. Alexandria Eng J. https:// doi.org/10.1016/j.aej.2017.08.024

12. Moonen P, Blocken B, Roels S, Carmeliet J (2006) Numerical modeling of the flow conditions in a closed-circuit low-speed wind tunnel. J Wind Eng Ind Aerodyn 94:699-723. https://doi. org/10.1016/j.jweia.2006.02.001

13. Calautit JK, Chaudhry HN, Hughes BR, Sim LF (2014) A validated design methodology for a closed-loop subsonic wind tunnel. J Wind Eng Ind Aerodyn 125:180-194. https://doi.org/10.1016/j. jweia.2013.12.010

14. Gartmann A, Fister W, Schwanghart W, Müller MD (2011) CFD modelling and validation of measured wind field data in a portable wind tunnel. Aeolian Res 3:315-325. https://doi. org/10.1016/j.aeolia.2011.07.002

15. Nisugi K, Hayase T, Shirai A (2005) Fundamental study of hybrid wind tunnel integrating numerical simulation and experiment in analysis of flow field. JSME Int J, Ser B 47:593-604. https://doi. org/10.1299/jsmeb.47.593

16. Hnidka J, Rozehnal D (2017) Pressure field in measurement section of wind tunnel. MATEC Web Conf. https://doi.org/10.1051/ matecconf/201710700075

17. Dryden HL, Schubauer GB (1947) The use of damping screens for the reduction of wind tunnel turbulence. J Aeronaut Sci 14:221-228. https://doi.org/10.2514/8.1324

18. Ghorbanian K, Soltani MR, Manshadi MD (2011) Experimental investigation on turbulence intensity reduction in subsonic wind tunnels. Aerosp Sci Technol 15:137-147. https://doi. org/10.1016/j.ast.2010.06.009

19. Kulkarni V, Sahoo N, Chavan SD (2011) Simulation of honeycomb-screen combinations for turbulence management in a subsonic wind tunnel. J Wind Eng Ind Aerodyn 99:37-45. https ://doi.org/10.1016/j.jweia.2010.10.006

20. Laws EM, Livesey JL (1978) Flow through screens. Annu Rev Fluid Mech 10:247-266. https://doi.org/10.1146/annurev.fl.10.01017 8.001335

21. Loehrke RI, Nagrib HM (1976) Control of free-stream turbulence by means of honeycombs: a balance between suppression and generation. J Fluid Eng 98:342-351. https://doi. org/10.1115/1.3448313

22. Roach PE (1987) The generation of nearly isotropic turbulence by means of grids. Int J Heat Fluid Flow 8:82-92. https://doi. org/10.1016/0142-727X(87)90001-4

23. Santos AM, Souza DB, Costa FO et al (2016) Effects of screens set characteristics on the flow field in a wind tunnel. J Phys Conf Ser. https://doi.org/10.1088/1742-6596/733/1/012001

24. Stathopoulos T (1984) Design and fabrication of a wind tunnel for building aerodynamics. JWind Eng Ind Aerodyn 16:361-376. https://doi.org/10.1016/0167-6105(84)90018-7

25. Scheiman J, Brooks JD (1981) Comparison of experimental and theoretical turbulence reduction characteristics for screens, honeycomb, and honeycomb-screen combinations. J Aircr 18:638-643. https://doi.org/10.2514/3.57538

26. ANSYS (2011) Fundamentals of ANSYS CFX, vol 15317. ANSYS, Canonsburg, pp 724-746

27. Azzawi IDJ, Mao X, Jaworski AJ (2016) Design, fabrication and characterization of low speed open-jet wind tunnel. Proc World Congr Eng II:1-6

28. Calautit JK, Hughes BR (2016) CFD and experimental data of closed-loop wind tunnel flow. Data $\mathrm{Br}$ 7:216-220. https://doi. org/10.1016/j.dib.2016.02.033 
29. Moonen P, Blocken B, Carmeliet J (2007) Indicators for the evaluation of wind tunnel test section flow quality and application to a numerical closed-circuit wind tunnel. JWind Eng Ind Aerodyn 95:1289-1314. https://doi.org/10.1016/j.jweia.2007.02.027

30. Canonsburg TD (2013) ANSYS CFX reference guide, vol 15317. Ansys Inc, Canonsburg, pp 724-746. https://doi. org/10.1186/1756-0381-3-1

31. Kato H, Obayashi S (2011) Integration of CFD and wind tunnel by data assimilation. J Fluid Sci Technol 6:717-728. https://doi. org/10.1299/jfst.6.717

32. Young PC, Buehrle RD, Balakrishna S, Kilgore WA (1994) Effects model of vibration on inertial attitude measurement devices. Nasa-Tm-109083
33. Ben Mosbah A, Flores Salinas M, Botez R, Dao T (2013) New methodology for wind tunnel calibration using neural networks-EGD approach. SAE Int J Aerosp 6:761-766. https://doi. org/10.4271/2013-01-2285

34. Caré I, Bonthoux F, Fontaine JR (2014) Measurement of air flow in duct by velocity measurements. EPJ Web Conf 77:1-5. https ://doi.org/10.1051/epjconf/20147700010

Publisher's Note Springer Nature remains neutral with regard to jurisdictional claims in published maps and institutional affiliations. 